\title{
Perseguir la herejía: libros prohibidos en el Colegio de la Santa Cruz de Querétaro
}

\author{
Idalia García ${ }^{1}$
}

Recibido: 8 de noviembre de 2018 / Aceptado: 26 de mayo de 2019

Resumen. Entender cómo los inquisidores buscaban herejes librescos en las instituciones de Nueva España, requiere adentrarnos en el trabajo más cotidiano de las diversas estrategias de la censura de libros. Una de éstas fue el expurgo, un mecanismo que permitió eliminar ciertas partes de los textos que se consideraron nocivos o peligrosos para la ortodoxia religiosa. En este trabajo analizamos parte de esta tarea con una de las visitas inquisitoriales ordenadas en 1716 para las bibliotecas institucionales de la Nueva España, en particular la que se realizó en la biblioteca del colegio franciscano de la Santa Cruz en Querétaro. Dicho proceso ha permitido relacionar sus documentos, con libros expurgados procedentes del periodo colonial y que se conservan en bibliotecas. A través de uno de sus protagonistas, Fray Ángel García Luque, podemos comprender el trabajo del expurgo y repensar la cerrazón de los inquisidores novohispanos. Es una forma de adentrarnos en la cultura escrita de este territorio americano.

Palabras clave: Visitas inquisitoriales; libros prohibidos; libros expurgados; bibliotecas coloniales; Colegio de la Santa Cruz de Querétaro; siglo XVIII.

\section{[en] Persecuting Heresy: Prohibited books at the Colegio de Santa Cruz of Queretaro}

\begin{abstract}
In order to understand how inquisitors identified bookish heretics within the institutions of New Spain, we must delve into the most common of the different strategies utilized for book censorship. One of these was expurgation, a mechanism that allowed for the elimination of certain parts of texts considered harmful or dangerous to religious orthodoxy. This article analyses a part of this process through the study of the inspection of the library of the Franciscan Collegiate School of Santa Cruz, in Querétaro, one of the inquisitorial inspections of the institutional libraries of New Spain, ordered in 1716. This analysis has allowed us to establish a relationship between the documents of the process and the expurgated books of the colonial period that have been preserved in libraries. Through the casestudy of one of the protagonists, Friar Angel Garcia Luque, we can understand the labor of expurgation and rethink the closed-mindedness of New Spain's inquisitors; a way of penetrating the written culture of this American territory.

Keywords: Inquisitorial inspections; Prohibited books; Expurgated books; Colonial libraries; Colegio de Santa Cruz de Querétaro; $18^{\text {th }}$ century.
\end{abstract}

Sumario. 1. Introducción. 2. Las múltiples formas de la censura. 3. Permiso para expurgar. 4. El expurgador denunciado. 5. Conclusiones: la vida cotidiana del expurgador. 6 . Referencias bibliográficas.

1 Instituto de Investigaciones Bibliotecológicas y de la Información. Universidad Nacional Autónoma de México (México).

E-mail: pulga@iibi.unam.mx 
Cómo citar: García, I. (2019) Perseguir la herejía: libros prohibidos en el Colegio de la Santa Cruz de Querétaro, en Revista Complutense de Historia de América 45, 113-132.

\section{Introducción}

Durante el periodo colonial todo libro, producido en el territorio novohispano o comerciado desde Europa, siempre fue considerado un vehículo ideal para transmitir la herejía. Por eso, fue objeto de las preocupaciones institucionales del Tribunal del Santo Oficio en Nueva España desde su fundación en 1571, aunque las estrategias de control se fueron implementando gradualmente. Así, la vigilancia de los libros se realizó durante más de doscientos años y se enfocó en mantener un efectivo control de aquellas obras consideradas peligrosas o sospechosas para el mantenimiento de la ortodoxia religiosa. Desde el Arzobispado de México, antes de la llegada de los inquisidores, algunos religiosos se preocuparon por denunciar y perseguir cualquier desviación religiosa, ya fuesen con libros prohibidos, ideas riesgosas o prácticas culturales sospechosas ${ }^{2}$. Estas ideas sobre la peligrosa condición del libro, se pueden apreciar de forma manifiesta en prácticamente todos los índices y edictos inquisitoriales, especialmente sí se trataba de obras escritas por aquellas posturas religiosas contrarias o diferentes a las que mantenía la Iglesia Católica Apostólica y Romana. Se trata de erradicar "las impresiones mendosas, depravadas, falsas, torcidas, violentas" $"$, que existen y afectan a la verdadera religión porque los libros pueden contener "errores, y doctrinas escandalosas, sospechosas y mal sonantes"4.

Con esta valoración, que compartían varios miembros de la sociedad, la Inquisición pudo aprovechar las normativas que controlaban al libro como una mercancía y que habían sido establecidos por la Corona Española desde el siglo XVI. Dichas normas, vigentes desde 1550, obligaban a registrar los títulos de los libros con detalle en la documentación necesaria para la transportación de mercancías que se realizaba desde Europa hacia América ${ }^{5}$. Trámite que cumplimentaban tanto mercaderes, religiosos que transportaban libros para alimentar las bibliotecas que tenían en todas sus casas americanas, como todas las personas que viajan entre territorios acompañados de libros. Esa misma lista presentada en Sevilla o Cádiz, debía entregarse a los inquisidores para su revisión y autorización, sin la cual los libros no podían embarcarse hacia el Nuevo Mundo. Una relación de libros que debía ser nuevamente revisada en los puertos de llegada por los funcionarios inquisitoriales. Todas estas copias han garantizado la conservación de numerosos testimonios que dan cuenta de ambos procesos, el controlador por los funcionarios de la Corona y el de los inquisidores.

Los tribunales de la Inquisición, como el novohispano, también emplearon otros mecanismos de control que afectaron la posesión de libros y en consecuencia a las bibliotecas. Esta tarea se realizó en dos frentes, uno particular y otro institucional. El primero, consistió en solicitar directamente a los poseedores de libros la entrega de una lista de las obras que se tuviesen en ese momento. Listas que hemos denominado "libros de uso", porque es una de las formas en que fueron denominadas por los propios poseedores. Hemos tenido noticia de estas listas porque algunas de

\footnotetext{
Férnandez, 1914.

Novissimus librorum prohibitorum et expurgandorum index, 1707, t. 1: f. 3v.

Cathalogus librorum, 1559: 3.

Maillard, 2012: 36.
} 
estas personas notificaron que lo hacen en cumplimiento de un edicto que todavía no hemos localizado. Por el contrario, sí contamos con evidencias de que ocurrió, que dicho testimonio existió, y que pudo estar fechado en 20 de octubre de 1612. En este, se ordenaba a los lectores "traer y dar memoria de todos los libros que cada uno tiene" así lo anotó Juan de Huerta y Gamboa ${ }^{6}$. Hoy contamos con un conjunto más que representativo de lectores que notifican a la Inquisición los libros que poseen ${ }^{7}$. Sin embargo, para algunos estudiosos dichas listas no se comenzaron a hacer hasta $1627^{8}$, pero ya encontramos algunas de finales del siglo XVI que forman parte de una investigación en proceso 9 .

El segundo frente, el institucional, ha sido conocido como "visita a las bibliotecas". Una actividad mencionada con frecuencia en la literatura especializada de diversas maneras ${ }^{10}$, considerando que se trataba de una actividad que realizaban frecuente los inquisidores ${ }^{11}$. Pese a esta mención, pocos autores precisan sobre qué tipo de bibliotecas se efectuaba, cuál era la instrucción que justificaba esta tarea y el procedimiento bajo el cual se realizaba. Nesvig considera como visita la que se realizó en la capital novohispana entre 1571 y 1572, de la que se conserva una memoria de los libros prohibidos que fueron recogidos y que atribuye a Bartolomé Ledesma ${ }^{12}$. Por su parte, Fernández del Castillo considera que es un proceso realizado en 1573 y coordinado por el inquisidor Hernández de Bonilla ${ }^{13}$. Un proceso semejante es el que Guibovich menciona que se realizó en Lima a partir de 1652, provocado por la denuncia del franciscano y calificador Juan Valero quien demandó una visita a las bibliotecas privadas y conventuales. Sin embargo, de ese proceso sólo se puede documentar la visita del Colegio de San Fernando de Quito ${ }^{14}$. Como el mismo autor declara, "las visitas documentadas de bibliotecas particulares son muy pocas, No se trataron de acciones ex profeso, sino por el contrario llevadas a cabo como parte de la investigación en los procesos de fe"15.

Sin embargo, un expediente del Archivo General de la Nación de México (AGN) de 1716, informa cómo los inquisidores ordenaban hacer esa visita para localizar los libros prohibidos que pudieran existir en las colecciones institucionales, tanto como para expurgar aquellos textos que así lo requerían. Aunque se ha mencionado que estas visitas también se realizaron en bibliotecas particulares, lo cierto es que cuando menos los inquisidores novohispanos facultaron la revisión únicamente de las bibliotecas de conventos, colegios y seminarios y otras casas religiosas. Efectivamente, en estos espacios cohabitaron colecciones de uso común y privado, siempre bajo autorización de la autoridad competente. A la fecha, no hemos encontrado noticia que se instruyera el mismo tipo de inspección para bibliotecas externas a este circuito. En

\footnotetext{
Listas de libros presentados al Oficio de la Inquisición en cumplimiento del Edicto de 1612. México, 1612. Archivo General de la Nación [México] (en adelante AGN), Indiferente Virreinal, Caja 4217, exp. 50, f. 43r.

García, 2016: 67.

Bethencourt, 1997: 255.

"La honestidad del confiable lector en Nueva España: control inquisitorial de libros durante el siglo XVII" (2018-2019)

Lea, 1983: 312.

Sarrion Mora, 2006: 21.

Nesvig, 2009: 231.

Fernández del Castillo, 1914: 471-495.

Guibovich Pérez, 2003: 122-126.

Ibídem: 127.
} 
esta misma idea, tanto Schons como Nesvig ya habían precisado que los inquisidores no invadían la vida privada buscando los libros prohibidos ${ }^{16}$.

Dicha revisión de bibliotecas no debe confundirse con las obligaciones establecidas para los libreros, quienes desde 1612 debían entregar anualmente memorias de los libros que tenían en venta. Las comisiones de expurgo a las que nos referimos forman parte de las actividades de control que la Inquisición realizó desde el siglo XVI, mediante la cual "promovió las actuaciones propias de una censura a posteriori, tales como visitas a librerías en busca de obras sospechosas y denuncia de los lectores de obras heréticas" ${ }^{17}$. Desde el Concilio de Trento, los índices y los edictos formaron parte de la jurisdicción exclusiva que se otorgaba al Consejo de la Suprema, y que marcaron una diferencia entre la censura de los libros romana y española ${ }^{18}$. Diferencia que justamente estructuró la censura entre los prohibidos y los expurgados, la reedición de obras expurgadas y, la venta de libros en todo territorio bajo el dominio de la Monarquía Española. Ahora bien, es importante comprender que:

La censura es el ejercicio de comprensión, reservado a doctores y teólogos, que interpreta y califica, y que se mantiene dentro del terreno doctrinal e intelectual. Exige un conocimiento preciso de la naturaleza de la verdad y de los grados del error y posee un lenguaje técnico propio, que permite nombrar y describir el disenso en todos sus grados y roturar conceptualmente el campo de las damnabilia. La prohibitio, en cambio, es un acto jurídico fuerte, que obliga y sanciona, aunque solo a partir del momento en el que se promulga. Por ende, la censura y sus principios conciernen a la teología dogmática, mientras que la prohibitio pertenece al ámbito de la ley y el derecho ${ }^{19}$.

Desde esta perspectiva, podemos entender cómo la censura inquisitorial refiere siempre al sistema ideológico que la soportó. Un sistema emanado por un conjunto muy particular de personas desde el Consejo de la Suprema en Madrid, y que se difundió a través de la acción de cada calificador en los tribunales territoriales. Estos miembros de la Suprema fueron quienes emitían el dictamen sobre los libros denunciados, sospechosos, prohibidos y expurgados. Los otros inquisidores, fueron los rastreadores de la herejía y garantes de la ortodoxia ${ }^{20}$, tanto en libros como entre reos, pero eran meros consultores religiosos. Lo que significa que califican pero no emiten sentencias, esa es tarea de otros más dedicados a las materias teológicas.

\section{Las múltiples formas de la censura}

En efecto, esos dos grupos que la censura tenía para controlar la posesión de los libros y en consecuencia su circulación, se estructuraron con tres frentes diferentes pero complementarios. Uno estuvo conformado por los calificadores de libros, quie-

\footnotetext{
Schons, 1949: 2; Nesvig, 2006: 16.

Rodríguez Besné, 2000: 223.

Ibídem: 224.

Vega, 2016: 73-74.

Torres Arce, 2001: 263.
} 
nes podían ser nombrados por el Inquisidor $\mathrm{General}^{21}$, o por un tribunal americano, como Antonio Manuel de Folgar, nombrado calificador de libros por la Inquisición de Nueva España ${ }^{22}$, Estos calificadores novohispanos, también contaban en ocasiones con el nombramiento de "corrector de libros". Así lo sugieren algunos documentos del siglo XVII. Por ejemplo, el secretario Juan de la Paraya, escribió que el 21 de agosto de 1625, los inquisidores Gonzalo Mejía Lobo y Francisco Bajan de Albornoz en audiencia de la mañana y,

habiendo visto las informaciones de la genealogía y limpieza del padre Fray Joan Henriques Predicador General de la orden de Santo Domingo; y provincial de la misma Religion en la provincia de san Hyppolito de Guajaca, y Natural de la Ciudad de Antequera en esta Nueva España, hechas por orden y mandado de este Santo Oficio, las aprobaron y dieron por bastante y atendiendo a las buenas prendas de Religion, letras y calidad del dicho Fray Joan Henriques le nombraron por qualificador y corrector de libros de este Santo Oficio en la dicha Ciudad de Antequera y Provincia de Guajaca, precediendo el juramento de fidelidad y secreto acostumbrado, el qual se cometio por mandato de los dichos señores Inquisidores para que le haga ante el licenciado Cristobal Barroso de Palacios, Comisiario de este Santo Oficio y Arcediano de la Santa Iglesia de Guajaca ${ }^{23}$.

Sin embargo, fueron los calificadores quienes resolvían las denuncias sobre los libros y establecían las diferencias entre aquellos que quedarían como prohibidos y expurgados. Pese a que la denuncia se hiciera en un tribunal periférico, como el novohispano, esta debía tramitarse ante el Consejo de la Suprema en Madrid ${ }^{24}$. La Suprema, fue el órgano responsable de tomar la decisión final que se hacía después del dictamen elaborado por un calificador designado para la tarea. Tal acción sí podía hacerse en un tribunal americano. Ahora bien, un libro denunciado no necesariamente se convertía en un libro prohibido, algunos podrían librarse de tan terrible acusación. Lo cierto es que estos afortunados, después del proceso, se convertían simplemente en sospechosos. Es decir, nunca salían del radar de las preocupaciones inquisitoriales. Como muestra de algunos acusados de papel y tinta se conservan varias denuncias de libros presentadas ante el tribunal de la Nueva España ${ }^{25}$, y algunos

21 Relación de méritos y servicios de Francisco Antonio Escandón, clérigo regular de la Orden de San Cayetano, lector jubilado de Teología en su Colegio de Salamanca, vicario general de las casas de España, calificador de la Inquisición, revisor y visitador de los libros y librerías de la Corte, examinador general del arzobispado de Toledo y vocal por las casas de España. Madrid, 9-VI-1717. Archivo General de Indias [España] (en adelante AGI), Indiferente General, 216, N. 120, Imagen 1.

22 Relación de méritos y servicios del doctor Antonio de Folgar y Amunárriz, presbítero domiciliario del arzobispado de México y colegial del Colegio de San Ildefonso de esa ciudad. Hijo de Ramón de Folgar y de Micaela de Amunárriz Garrido. Natural de la ciudad de México, 4-VI-1746. AGI, Indiferente General, 229, N. 50, Imágenes 60-61.

23 Nombramiento de fray Juan Henríquez como calificador y corrector de libros del Santo Oficio en la Villa de Antequera. México, 30-VIII-1625. AGN, Indiferente Virreinal, Caja 5255, f. 1r. En este trabajo todos los textos que se extraen de documentos antiguos se transcriben tal y como se encuentran con la finalidad de respetar la ortografía de la época.

24 Rodríguez Besné, 2000: 230.

25 A modo de muestra: Denuncia del libro titulado Manual de Confesores de Enrique Villalobos. México, S.F. AGN, Indiferente Virreinal, Caja 1062, exp. 25, 1 folio. 
de los dictámenes resultantes de esas denuncias ${ }^{26}$. La respuesta peninsular daba por efecto un edicto que se publicaba en cada territorio y notificaba a la sociedad cuando un libro quedaba considerado como prohibido ${ }^{27}$. De los expurgados, también se daba noticia por edicto pero se actuaba directamente con cada índice que se publicaba, cuando menos desde 1584. Pero estos libros generaron otra actividad de control que aquí mencionamos.

Otra forma de censura corresponde a la licencia para leer libros prohibidos, que se podía otorgar a individuos e instituciones ${ }^{28}$. Dicha licencia debía solicitarse por escrito y argumentar la necesidad de esa lectura, que podía ser general o enfocarse en un solo libro. Así, se explicaba si esa necesidad se justificaba para el cumplimiento de ciertas funciones o beneficios. Esta condición aparentemente tan flexible, favoreció que en ciertos momentos se otorgasen un número considerable de esas licencias, y por lo cual los inquisidores reclamaban ya desde 1602 que:

ha crecido demasiado el numero de las licencias de leer libros de herejes o sospechosos de herejia o que ya estan reprobados y comdemnados impetradas por ciertas causas y pretextos y que hay peligro que por esto la permission de leer los dichos libros pueda ser de mayor daño para los ignorantes que de provecho para los sabios, principalmente en las partes que por la Gracia Divina no están tocadas por la cruel pestilencia de las herejías ${ }^{29}$.

Lo cierto es que estas licencias se siguieron aprobando a lo largo de todo el periodo virreinal. De tal forma que las prohibiciones de los edictos debían especificar que, en ciertos casos, también aplicaban para quienes tenían licencia para leer prohibidos. Finalmente en la estructura de control, se encontraba el censor o expurgador. Una persona que actuó en casos específicos. Un ejemplo es la comisión para realizar el expurgo de una o varias colecciones que ahora podemos conocer con mayor detalle. Cada una de estas actividades fue realizada por un grupo social conformado por personas con un reconocido conocimiento teológico, pero especialmente con una amplia cultura de libros. También olvidamos que todas estas acciones inquisitoriales, sólo se pueden explicar con el concierto de una gran parte de la sociedad de su tiempo. Sin embargo, el impacto social y las manifestaciones que tuvieron tales controles librescos en Nueva España han sido poco estudiados. Igualmente, los inquisidores novohispanos como funcionarios y como personas son personajes coloniales que tampoco han generado mucho interés de investigación. De estos últimos, las últimas evidencias documentales muestran cómo eran personas que se encontraban en los dos bordes de la censura de libros: como inquisidores y como lectores. Sabemos que en ambos cumplimentan las normativas y que, a veces, también las transgredieron ${ }^{30}$. Condición que no debe extrañar, pues ambas son las caras de una misma práctica cultural.

26 Por ejemplo: Calificación por el calificador Francisco de la Encarnación de la provincia de Manila del libro Respuesta de Fabricio Silote a la carta de Matheo Fadrique, con el resultado de libro prohibido. Ámsterdam; Ginebra. Manila, 13-VI-1749. AGN, Indiferente Virreinal, Caja 236, exp. 17, 2 folios.

27 Edicto que hace el Santo Oficio, del libro prohibido titulado Guía de Forasteros de México, que da noticia de mujeres prostitutas. Mexico, 10-VI-1785. AGN, Indiferente Virreinal, Caja 5018, exp. 48, 1 folio.

28 Licencia para que el Seminario Conciliar pueda comprar y retener los libros prohibidos. Guadalajara, 23-VII1799. AGN, Inquisición 1094, exp. 4, f. 297r.

29 Revocación papal de licencias de libros prohibidos. México, 26-01-1612. AGN, Indiferente Virreinal, Caja 791, exp. 15 , ff. $11 \mathrm{r}-12 \mathrm{r}$.

30 García - Montiel, 2010: 90-97. 


\section{Permiso para expurgar}

Líneas atrás mencionamos la existencia de un grupo específico de personas que fueron comisionados para realizar los expurgos de los libros en momentos específicos. Al menos, la evidencia histórica nos ha mostrado que esta autorización está directamente relacionada con esa visita a las bibliotecas privadas que varios textos que nos anteceden han apuntado se realizan de manera frecuente ${ }^{31}$. Dicho tipo de visita se realizó como un medio más de fiscalización social sobre los libros prohibidos, pese a que algunos lectores tuviesen una licencia para leerlos. Un grupo que pudo ser bastante más amplio de lo que hemos supuesto. De cualquier manera, tales medidas afectaron la libre disposición de los libros pero nunca limitaron su circulación como testimonia la documentación inquisitorial que se conserva.

El proceso al que nos referimos, del que da cuenta todo un expediente fechado entre 1716 y 1719 , es el primer testimonio novohispano que nos acerca al procedimiento de la visita de bibliotecas religiosas en un territorio tan extenso. La documentación ahí contenida permite comprender otros aspectos de la censura inquisitorial, más allá de las normativas o de los discursos institucionales pues muestra el efecto práctico de las acciones de control sobre los libros. Tristemente sólo hemos encontrado este expediente, aunque contiene bastante información para comprender otras visitas anteriores. Ésta comenzó el seis de mayo de 1716, cuando los inquisidores mandaron armar el edicto que daría conocimiento en el Virreinato de la Nueva España de la edición del Index Librorum Prohibitorum de 1707 elaborado por Diego Sarmiento. Como la normativa había establecido, al término de noventa días de esa comunicación, debía realizarse el expurgo de todos los libros que hubiere "en cada paraxe" y en lo que correspondía a las bibliotecas de los regulares mandaron:

dar comisión y facultad a los provinciales de cada Provincia para que en cada uno de los conbentos de ella puedan nombrar uno, o dos religiosos los que fueren de su mayor satisfacción y cometerles en nombre del Santo Oficio la licencia y facultad para que puedan expurgar la librería de cada Conbento, y de los religiosos particulares de el ${ }^{32}$.

Para tal instrucción se generaron unos documentos particulares que en el testimonio se denomina comisiones de expurgo. Estos, son formularios en su mayoría impresos, y fueron llenados por los provinciales otorgando la responsabilidad de la tarea a uno o varios religiosos. Cada una de estas comisiones está conformada por tres partes: la comisión misma (que puede ser impresa o manuscrita), el informe del religioso encargado y de ser el caso, la memoria de los libros prohibidos que deben recogerse y enviarse a la sede del tribunal en la capital virreinal. Dichos libros, al parecer no todos se destruyeron como se ha considerado ${ }^{33}$. Al menos eso parece indicar la documentación conservada relativa a ciertos asuntos de la librería del Santo

31 Bethencourt, 1997: 242 o Pardo, 1991: 33-36.

32 Inquisición de México. Año de 1716. Cuaderno de las calificaciones que remitieron los Provinciales de las Religiones de este Reino de la Nueva España, y de las Islas Filipinas, de haberse expurgado según el Nuevo Expurgatorio el año de 1707, los libros de las Librerías de los Conventos de cada Provincia, y de los Religiosos particulares de ellos [en adelante Inquisición de México. Año de 1716. Cuaderno de las calificaciones]. México, 17-VII-1717. AGN, Inquisición 763, exp. 2, ff. 132r-132v.

33 Plata, 1997: 174. 
Oficio, uno de los cuales es la indebida venta de libros prohibidos que se realizó en 1771 y el otro el "Indice alphabetico de los libros y Authores" que se elaboró para facilitar la localización de libros donde se anotó la presencia de libros duplicados ${ }^{34}$. Ciertamente aún queda por determinar sí existió una división entre la biblioteca de los inquisidores, necesaria para las actividades que realizan, y una colección conformada con los libros prohibidos que se iban recogiendo.

Otra cosa muy distinta ocurrió con los libros expurgados que son una característica propia de la Inquisición española, como una "opción del consenso" entre libreros e inquisidores ${ }^{35}$. Esa es la razón, por la que requirieron otra forma más específica de control pues la circulación no debía impedirse sino solamente controlarse la lectura de ciertos pasajes. El expediente citado comienza en 1716, pero contamos con evidencia bibliográfica de expurgos anteriores realizados desde 1585 y también de 1612, 1632 y 1640. Es decir todos correspondientes con los índices inquisitoriales publicados en esos años ${ }^{36}$. Ahora bien, la mayor parte de las comisiones que integran este expediente sólo contienen las dos primeras partes que hemos mencionado. A saber, la comisión y el informe del expurgador. Lamentablemente las memorias de libros conservadas son escasas, y corresponden a la Provincia de San Diego, la Provincia del Santo Nombre de Jesús, la librería del Colegio de la Santa Cruz de Querétaro, la librería del Convento de Santo Domingo de Oaxaca ${ }^{37}$, y la Provincia de San Hipólito Mártir.

También se encuentran otros documentos, como aquellos en los que los religiosos solicitan más tiempo para realizar la tarea de expurgación, como lo hizo el franciscano Joseph Cillero quien pidió "tiempo ilimitado"38, o el dominico Fray Francisco de Aguirre quien pidió "dos, ò tres meses" para expurgar los libros de Santo Domingo de México por ser "muy crescido su número" ${ }^{39}$. Un reciente estudio español permite apreciar diferencias y semejanza en estas visitas ordenadas por el Santo Oficio en febrero de 1747 , en cumplimiento de un edicto de febrero de $1747^{40}$. A diferencia del novohispano, en este se trata de un intercambio epistolar entre las comunidades religiosas, quienes informan sobre sus respectivas bibliotecas, y los inquisidores preocupados por la custodia y lectura de los libros prohibidos.

En dicho expediente se conservan más noticias de libros que en el novohispano, e información sobre quienes tenían licencia para leer libros prohibidos. Existen algunas semejanzas en ambos expedientes. La primera es que al igual que en Nueva España, no existe mención alguna sobre los conventos femeninos ${ }^{41}$. La segunda, que en algunas entidades se pueden encontrar listas de los libros prohibidos y expurgados, incluso algunas con bastante información. El caso español es muy interesante, porque además hay noticias de quienes ejercían el oficio de bibliotecarios y, por tanto ciertos detalles sobre esta actividad. En el caso novohispano sólo tenemos noticia

34 Índice alfabético de los libros y autores que contiene la librería del Secreto de este Santo Oficio. México, 27-051771. AGN, Inquisición 1135, exp. 14, ff. 319r-322r.

35 Peña Díaz, 2015: 40.

36 Pardo, 1991: 47-94.

37 Esta lista es la base del trabajo en desarrollo "Unas cuantas preocupaciones inquisitoriales: libros prohibidos en Santo Domingo de Oaxaca", que fue presentado en el Primer Congreso Internacional de Historia de la Orden de Predicadores en América, celebrado en la ciudad de México en abril del 2013.

38 Inquisición de México. Año de 1716. Cuaderno de las calificaciones, f. 139r.

39 Ibídem, f. 148r.

40 Suboh Jarabo, 2017: 115-116.

41 Ibídem: 127. 
del archivero y provincial en Oaxaca, Leonardo Levanto, quien fue responsable de la tarea del expurgo.

Aquí interesa analizar esta práctica inquisitorial a través de un caso puntual: el de un expurgador que manifiesta algunas dudas en la tarea que se le ha encargado. Es el caso de Fray Ángel García Duque, confesor franciscano, quien fue comisionado en este proceso citado para revisar los "dos mil libros" $"$ de la librería del Colegio de la Santa Cruz de Querétaro de la Provincia de San Pedro y San Pablo de Michoacán. Dicha comisión se expresó, al igual que en todos los casos, de la manera siguiente:

Por orden y comission particular que tengo de los Señores Inquisidores Apostólicos del Santo Officio de la Inquisición de esta Nueva España, por la presente doy licencia al Reverendo Padre Fray Angel García Duque para que pueda expurgar los Libros del Collegio Appostolico de la Sancta Cruz de esta Ciudad y de sus religiosos en particular conforme al nuevo Índice del año passado de mill setecientos y siete; advirtiendo que lo que assi expurgare, y borrare sea de manera que no se pueda leer, y en la primera oja del libro expurgado ponga la nota firmada de su nombre, en que diga, que en virtud de comission del Santo Officio, y segun el dicho Expurgatorio del año de siete, expurgô aquel Libro en tantos de tal mes, y año: $Y$ los Libros que hallare prohibidos intotum los embiara para entregarlos en el Tribunal de dicho Santo Officio, juntamente con esta licencia original y certificacion al pie de ella de haverla cumplido, y de quedar expurgados todos los Libros prohibidos. Fecho en este Convento de Queretaro en $1^{\circ}$ de mayo de este año de 1717 Fray Joseph Picarzo Maestro Provincial ${ }^{43}$.

En el informe correspondiente, integrado a esta comisión y fechado el 20 de octubre de ese mismo año, el franciscano García Duque anotó "haver cumplido en todo, y por todo" lo que se le había encargado. Tarea que incluía recoger y entregar los libros prohibidos in totum al Ministro Provincial, para que éste junto con todos los demás recogidos en la provincia fuesen entregados en el Tribunal del Santo Oficio. Tres meses antes del informe que envió a su provincial, Fray Ángel elaboró una "Memoria de los libros prohibidos que hallê y tengo recogidos de la librería de Santa Cruz de Queretaro" "44. Una de las pocas relaciones de libros contenidas en este expediente y que enumeramos líneas atrás. Como se puede apreciar no es muy grande, son los títulos siguientes:

Libros prohibidos absolute

Vn tomo (in folio) intitulado: Epistolias y evangelios para todo el año. Su author Fray Ambrosio de Montesinos. en castellano. $1^{45}$.

Dos tomos (in folio) su titulo: Espejo de consolacion, el un tomo es primera parte. el otro tomo 456 parte. Su author Fray Juan de Dueñas. en castellano. $2^{46}$.

42 Inquisición de México. Año de 1716. Cuaderno de las calificaciones, f. 208r.

43 Ibídem, f. $231 \mathrm{r}$.

44 Ibídem, ff. 224r.-224v.

45 Montesino, 1608. Esta es la edición que prohíbe el Índice de 1707, que reconoce como segunda edición de la realizada en Medina del Campo en 1586. Sin embargo, prohibe "qualquiera impresión". Novissimus librorum prohibitorum et expurgandorum index, 1707, t. 1: 57.

46 Dueñas, 1546. Se prohiben todas las ediciones "hasta que se enmiende"; al parecer esto fue hasta 1550. Novissimus librorum prohibitorum et expurgandorum index, 1707, t. 1: 755. 
Ocho tomos (in folio) intitulados: De los prodigios de la omnipotencia, y milagros de la gracia, en la Vida de la venerable sierva de Dios Cathalina de San Juan. Los quatro son segundas partes, y los otros 4, terceras. Su author de Alonso de Ramos. En castellano. $8^{47}$.

Dos tomos (in quarto) su titulo: Thesoro de Chripstianos que para cada dia les dejô

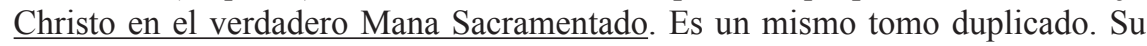
author Fray Antonio Velazquez Pinto. En castellano $2^{48}$.

Dos tomos (in quarto) su titulo: A la Serenissima Señora Ynfanta Sor Margarita de la Cruz Religiosa descalza del Real Convento de Franciscas descalzas de Madrid. Es un mismo tomo duplicado. Su author Fray Yuanetin Niño. En castellano. $2^{49}$.

Un tomo (in octavo) su titulo: Migajas caîdas de la Mesa de los Santos. Su author Fray Francisco del Castillo. En castellano. $1^{50}$.

Quatro tomitos muy pequeños: sus títulos. A.B.C. de Jesus en la Escuela de Maria, y de Joseph. Y Vía Sacra. Su author: Fray Sebastián de la Chica. En castellano. $4^{51}$.

Vn tomito muy pequeño. su titulo: Septenario del Glorioso Patriarcha San Joseph, en reverencia de los siete dolores y siete gozos. Sin nombre de author. En castellano. $1^{52}$.

Vn tomo (in octavo) su titulo: Manual de Predicadores, argumento de todos los Psalmos. su author: Fray Salvador de Mallea. Parezeme se prohibe por la regla V. del expurgatorio, por ser este libro: Compendio del libro de Escritura en lengua vulgar castellana ${ }^{53}$.

$=$ Libros prohibidos, donec expurgentur, vel donec recognoscantur=

Vn tomo (in octavo) su titulo: In totaz Genesim nonminus exudite, quaz Catholice enarrationes. su author Joannes Ferus. $=$ en latin $={ }^{54}$.

Vn tomo (in octavo) su titulo: Legatus. su author Fredericus de Marselaer. en latin $^{55}$.

Agosto 16 de este presente año de 1717.

Fray Angel García Duque

Expurgador de libros por el Santo Tribunal de la Ynquision de Mexico.

47 Ramos, 1692. El Índice incluye la primera parte impresa en 1689, de la que no hemos encontrado ejemplar, así como la segunda y tercera parte impresas en 1692. Novissimus librorum prohibitorum et expurgandorum index, 1707, t. 1: 776 .

48 Velazquez Pinto, 1664. Esta es la edición que menciona el Índice, pero prohíbe "otra qualquier impression". Novissimus librorum prohibitorum et expurgandorum index, 1707, t. 1: 61.

49 Niño, 1632. Esta es la edición que se prohíbe. Novissimus librorum prohibitorum et expurgandorum index, 1707, t. 1: 754 .

50 Castillo, 1620. Esta es la edición que se prohíbe. Novissimus librorum prohibitorum et expurgandorum index, 1707, t. 1: 440 .

51 Acerca de esta referencia de Sebastian de la Chica (O.F.M.), no hemos encontrado ni al autor ni edición conservada con ese título, y el Índice tampoco indica ciudad de impresión y año. Parte de sus obras fueron impresas en Madrid y Zaragoza en 1671 Ibídem, t.2: 225. La obra es mencionada en: Ezcaray, 1691: 129.

52 La más antigua edición que hemos encontrado es esta: Septenario, 1729. Es muy posible que la edición que recogió Fray Ángel García Duque fuese impresa con anterioridad por cualquier impresor activo antes de 1717.

53 Mallea, s.a. Esta obra no está incluida en el Índice. Novissimus librorum prohibitorum et expurgandorum index, 1707, t. 2: 224-225.

54 Wild, 1564. El Índice no indica una obra específica sólo dice del autor "Fraude Sectatorium vitiatus". Novissimus librorum prohibitorum et expurgandorum index, 1707, t. 1: 726.

55 Marselaer, 1644. Aparentemente se trata de esta edición. Novissimus librorum prohibitorum et expurgandorum index, 1707, t. 1: 438. 
Esta memoria tiene los títulos subrayados que hemos identificado aquí. Como se aprecia sigue presente el famoso "Fero" o "Ferus" que se persigue en Nueva España desde la segunda mitad del siglo XVI. Se trata del franciscano alemán Johann Wild, quien predicó contra los luteranos y escribió varios libros. Pese a ello, varias partes de su obra fueron consideradas riesgosas y de ahí que se mantuviera bajo la atenta mirada inquisitorial desde 1584. Quizá, porque una parte importante de su obra estuvo dedicada a los comentarios del Antiguo Testamento. La obra de Wild fue expurgada, como lo indicaban los índices, en numerosas bibliotecas tanto peninsulares como coloniales ${ }^{56}$. Pero hay algo más interesante en este testimonio. Unos meses antes de elaborar su informe, en julio, el franciscano explicó en una carta cómo había hecho la tarea de expurgación, algunas dudas y que entre los libros revisados había "algunos pocos de particulares religiosos", pero que "libros de personas particulares seculares no han venido a mi, si vinieren, los expurgarê y recogerê los prohibidos" 57 . Esta noticia junto con otras similares que se mencionan en los documentos del citado proceso, confirman la existencia de las bibliotecas privadas en las casas religiosas paralelas a las bibliotecas comunes o de uso general. Por otro lado, la mención a libros de seculares nos hace pensar que estas son las únicas colecciones particulares a las que podían acceder los inquisidores. Son bibliotecas de las que efectivamente tenemos noticia, no solamente porque estos documentos las mencionan, sino porque también son aludidas en las constituciones y reglas de las órdenes religiosas.

\section{El expurgador denunciado}

De Fray Ángel, tenemos pocas noticias. Sabemos que fue peninsular, hijo de la Provincia de Santiago en León, predicador apostólico y misionero de Propaganda Fide, fundador del Colegio de Guadalupe en Zacatecas, Ex lector de Filosofía y Sagrada Teología y, Guardián del Colegio de Santa Cruz de Querétaro, porque así lo declaró en su solicitud para calificador del Santo Oficio en mayo $1712^{58}$. Quizá la denuncia inquisitorial de la que fue objeto, presentada el 24 de septiembre de 1711, fue la que motivó esta solicitud. En efecto, para documentar el optimismo este franciscano fue denunciado por el Bachiller y Presbítero Juan Antonio Pérez y Espinoza, por "la doctrina que en el discurso del sermón" que predicó el 14 de septiembre de ese mismo año, en el colegio del que era guardián y que dedicó "en Gloria y Exaltación de la Santa Cruz".

La materia de la denuncia fueron las protestas del predicador sobre los eclesiásticos y su comportamiento en la celebración del Corpus Cristi de esa ciudad, porque "siendo el día mas pacifico que avia, se ha hecho el día mas escandaloso perdiendo el decoro al Santo Sacramentado con notificaciones y disturbios" 59 . Al parecer el problema puntual fue que la opinión de Fray Ángel, afectaba el asunto de las preeminencias de los religiosos justamente en los eventos públicos. Espacios del orden

56 Hampe Martínez, 1987: 539.

57 Inquisición de México. Año de 1716. Cuaderno de las calificaciones, fol. 208r.

58 Nombramiento de calificador en ínterin a favor de Fray Angel García Duque [en adelante Nombramiento de calificador, 1712]. México, 4-V-1712. AGN, Inquisición, vol.745, exp. 66, f. 639r.

59 Denuncia de un sermón que predicó el día 14 de Septiembre de 1711 el Reverendo Padre Guardián del Convento de Santa Cruz de Querétaro Fr. Angel García Duque en la fiesta de la Exaltación de la Santísima Cruz [en adelante Denuncia de un Sermón, 1711]. México, 24-IX-1711. AGN, Inquisición, vol. 750, exp. 37, ff. 591r-604r. 
social bastante controvertidos y no exentos de conflictos, pues no estaban regulados y en los cuales cada grupo demandaba posiciones de privilegio ${ }^{60}$. Para amenizar el debate el franciscano era considerado:

sugeto tan conocido como estimado por su virtud y letras no solo entre los eclesiasticos por su subtil discurrir sino mucho mas entre los Republicanos y Seculares que atienden sus dictamenes por oraculos y se goviernan los mas principales por sus consejos ${ }^{61}$.

No por esta estimación, la denuncia fue descartada. Todo lo contrario, el franciscano fue notificado cuando comía con su comunidad y aceptó no sólo presentarse a explicar su opinión sino que también entregó el texto en cuestión escrito en nueve folios, tal y como se lo solicitaron, ante el Notario del Santo Oficio en la Ciudad de Querétaro y Presbítero Joseph Xavier de Ayala quien le notificó la denuncia de la que era objeto el 24 de septiembre del mismo año.

Pese a que los inquisidores, quienes dictaminaron el sermón, consideraron no hallar "cossa que contradiga ni a la fee, buenas costumbres, Dogmas, ni decretos pontificios", Fray Angel García Luque se presentó ante el Capellán Juan Antonio Lobato el 12 de Febrero de 1712 en la ciudad de México, y ahí expuso sus razones "libre de censura" y mantuvo su opinión sobre el comportamiento de los eclesiásticos pues algunos actuaban "más por vanidad que por edificación". Para el 19 de junio de este año, Fray Ángel, recibió el nombramiento de Calificador del Santo Oficio que se le había concedido. Así aceptó y se obligó "a guardar secreto ante todos los cassos y cossas que se le ofrecieren, y fueren ordenadas y encomendadas por dichos Señores Inquisidores". Un nombramiento que fue validado precisamente por el mismo notario que le notificó la denuncia de su sermón ${ }^{62}$.

Este año también se imprimió otro sermón de su autoría titulado Elogio sepulchral a las venerables memorias de el Padre Fr. Antonio de los Angeles, impreso en la capital novohispana ${ }^{63}$. Casi una década después, en 1721, Fray Ángel modificó una memoria de deudas y legados que había dejado el queretano Francisco de Alzaga, con el concierto de éste y su padre, en virtud de que fue el confesor de don Francisco, y también intervino para resolver los conflictos relacionados con la adquisición un solar cercano al Colegio Apostólico donde residía ${ }^{64}$. Por esto, resulta tan interesante el documento que elabora Fray Ángel García Duque expresando ciertas dudas porque nos acerca a una persona que se relaciona con su mundo pese a su compromiso con el secreto. Así lo hizo, apelando a su nombramiento por el provincial franciscano, otorgado el 24 de abril de 1717 para hacer la revisión conforme al expurgatorio de 1707 . En el segundo párrafo de este documento, Fray Ángel comienza expresando:

En los libros que he expurgado no he tenido duda, porque he procurado enterarme bien del expurgatorio, y arreglarme a el, poniendo al principio de cada libro expurgado lo que me manda poner firmado de mi nombre ${ }^{65}$.

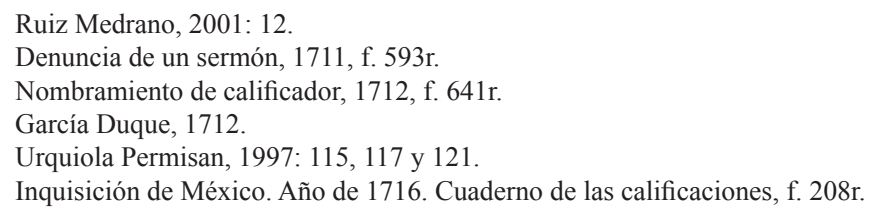


Este apunte de Fray Ángel remite a la instrucción principal de la comisión en materia de expurgo, pues como se ha visto ordenaba borrar lo que el expurgatorio indicaba, de forma que no se pueda leer y que se anote en la primera hoja del libro que fue expurgado por orden del Santo Oficio, con su nombre e indicando el Índice al que corresponde. Inmediatamente después desea precisión, nuestro franciscano entra ya en materia, informando que en relación al expurgo del Ramillete de flores divinas, de Bernardo de Sierra, ha expurgado "tomando por norma uno que vi expurgado y firmado del Señor Inquisidor mayor Don Joseph Cienfuegos".

No sabemos cuál edición es la que se refiere el franciscano, pues aparentemente solo una fue prohibida y las demás debían expurgarse. Esta obra, suponemos que ya expurgada, tuvo una importante circulación como se aprecia en varias licencias inquisitoriales que autorizaron su llegada a territorios americanos ${ }^{66}$. Impacto que veremos también reflejado en otros testimonios como las memorias de libros que los lectores debían entregar a la Inquisición cada vez que se demandaba por edicto. Una lista que igualmente revisaba un calificador. Así, el revisor Pedro de Castillo y Vergara anotó en una de estas memorias:

Expurgado. Otro librito de Ramillete de divinas flores compuesto por bernardo de Sierra soldado de los cien continuos hijosdalgo dela casa de Castilla, con privilegio a costa de doña Maria de Rivera su mujer y herederos, por Bernardo Villadiego año de 1681 .

Este caso procede de la lista de libros entregada por Manuel de Quiroga, un carrocero, en $1716^{67}$. El libro a pesar de ser prohibido, no generó un gran escándalo ni ninguna persecución del lector o de su círculo social cercano. Tales memorias de los particulares son a las que nos hemos referido como "libros en uso", porque las personas suelen escribir "los libros que tengo" o "los libros de mi uso" en las memorias que entregaron a la Inquisición siempre por petición expresa de ésta. En cierta medida reflejan sólo un momento en la conformación de una biblioteca, ya que esa colección podía crecer o disminuir determinada por la fortuna de sus propietarios. Pero sin duda se trata de ejercicios personales de cierta honestidad.

Es probable que las listas de particulares sean más abundantes que otras, pero tampoco hemos realizado un inventario de todas las que se han conservado para determinarlo. Como ejemplo de estos documentos, podemos apreciar esta: "Memoria de los libros que yo Mateo de la Torre tengo soy vecino de Santa María la Redonda" ${ }^{68}$. No hay duda de que son documentos similares a los que se utilizaban para un traslado de ciudad o de territorio, como este: "Lista de los libros que conduce para su uso en México, don Silvestre Diaz de la Vega, electo contador general de la Renta de Taxco de Nueva España" ${ }^{69}$. Ambos testimonios contienen la relación de los libros que en ese momento tenía una persona, pero sólo algunos documentos responden a la publicación de un edicto; otros a traslados entre ciudades o adquisiciones desde Europa.

66 Licencias inquisitoriales. siglos XVII-XVIII. AGI, Contratación 674.

67 Memoria que hago yo Manuel de Quiroga maestro carrocero de los libros que tengo. México, 12-VI-1716. AGN, Inquisición 763, exp. 3, f. 357v.

68 Memoria de los libros de Don Mateo de la Torre, vecino de Santa María la Redonda. México, S.F. AGN, Indiferente Virreinal, caja 826, exp. 2, 1 folio.

69 Lista de los libros de Silvestre Diaz de la Vega. México, S.F. AGN, Inquisición 1159, exp. 3, ff. 148r.-150v. 
Ahora bien, también encontramos el Ramillete en testimonios semejantes, sin poder determinar la edición, en la colección de otro vecino de la ciudad. Fue registrado de la siguiente manera: "1 Ydem Ramilletes de Divinas flores por Bernardo de Siera"70, y al revisar la lista los inquisidores no marcaron este libro como prohibido ni mandaron que debía ser entregado ante el Tribunal. La presencia de esta obra en otros testimonios, prohibida en una de sus ediciones, amerita una revisión más detallada para desmenuzar cuáles eran las ediciones que circulaban en esa época y comprender cómo actuaron los inquisidores en un caso tan particular ${ }^{71}$. Especialmente considerando el alto número de ejemplares de esta obra que circularon durante el periodo colonial, tan solo en 1723 se enviaron "977 ramilletes de divinas flores" $"$.

En su documento continúa expresando el franciscano nociones sobre su trabajo de expurgo que son más interesantes, ya que explica que ha actuado en esa forma "porque me dijeron avia respondido assí ese Santo Tribunal en consulta, que de esta ciudad de hizo sobre dicho libro"73. Este testimonio ayuda a explicar por qué el propio franciscano elaboró sin temor alguno otro documento que tituló justamente Dudas que se me han ofrecido, sobre algunos libros y tratados ${ }^{74}$. Es un documento breve, el más sugestivo, que antecede justo a la memoria de libros prohibidos que Fray Ángel encuentra y recoge que hemos transcrito líneas atrás y en la cual registró once títulos en veinticuatro tomos. Aquí, entre sus dudas Fray Ángel se expresa sobre las novenas de personas devotas "impresas en culto y devocion de los Santos, y estan saliendo cada día de las impressiones sin nombres de sus authores". El franciscano quiere determinar si se incluyen o no en la regla diez del expurgatorio, que fue dedicada precisamente a todas las obras "impresas y divulgadas" sin autor desde 1584.

Seguidamente pide que se le precise un título (Compendium theologicae veritatis $)^{75}$, porque no está seguro "si es un libro pequeño y latino" que es "mui familiar a los escholasticos de mi religion". En suma, el franciscano duda que un libro tan "celebrado" por sus hermanos religiosos, sea al mismo tiempo considerado un libro prohibido por el Santo Oficio. Pese a lo cual, para no pecar de inocente lo tuvo "recogido", aun cuando podría de una obra de San Buenaventura, Santo Tomás o San Alberto Magno. Las dos últimas dudas que enumera Fray Ángel están relacionadas con dos autores. El primero "Christophorus a Capitefontium", que afirma se encuentra en el expurgatorio, pero no está seguro sí la obra localizada en Querétaro sea una de las prohibidas ${ }^{76}$. El fraile anota como título de este autor, "Compendium privilegiorum Fratum Minorum". La otra duda está relacionada con un título muy semejan-

70 Lista de los libros del difunto Don Carlos de Silva, contador general del Tabaco. México, S.F. AGN, Inquisición 1159, exp. 3. fol. 51v.

71 Se ha analizado solamente la acción institucional novohispana ante las denuncias de esta obra, pero no los expurgos ni la amplia circulación de esta obra. Véase: Moreno Gamboa, 2016.

72 Solicitud autorizada de Joseph Guerrero. Licencias de la Inquisición para cargar libros. Sevilla, 1723. AGI. Contratación 674, f. 497r.

73 Inquisición de México. Año de 1716. Cuaderno de las calificaciones, f. 208r.

74 Ibídem, f. 209r.

75 La obra mencionada se encuentra registrada en la página 240 del Novissimus librorum prohibitorum et expurgandorum index, 1707, t. 1, sin más información de la que mencionó Fray Ángel en el expurgatorio, tal y como él lo había citado.

76 El índice registra en la página 28 a "Christophorus a Capite Fontium", que podemos identificar como Christophe de Cheffontaines (1512-1595). En efecto, varias de sus obras estaban prohibidas en 1707. 
te al anterior, aunque el franciscano precisa que se trata de otro librito "distinto" 77 , que carece de autor.

Fray Ángel como expurgador, fue muy puntual en su tarea. Como hemos visto, su propio trabajo como predicador había estado bajo sospecha. De esta acusación tanto el texto como el autor salieron muy bien librados pese a que la denuncia parecía bien fundamentada. Sabemos también que este franciscano fue uno de los fundadores del Colegio Apostólico de Propaganda Fide de Nuestra Señora de Guadalupe de Zacatecas en 1707, donde también fue guardián. Por la denuncia inquisitorial sabemos que para 1711 ya había regresado al Colegio de Santa Cruz de Querétaro, donde se había fundado el primer Colegio de Propaganda Fide de la Nueva España. Es decir, desde donde los franciscanos organizaban y formaban a los misioneros de su orden.

\section{Conclusiones: la vida cotidiana del expurgador}

La fortuna ha querido conservar un conjunto de cartas personales, escritas entre 1714 y 1723, que muestran una faceta personal de este franciscano expurgador ${ }^{78}$. Estas misivas dan cuenta de que Fray Ángel seguía viviendo en Querétaro en 1723. Desde su colegio, envío el pésame a su amigo Juan Manuel de Argüelles y Miranda, por la muerte de su padre ${ }^{79}$. Es gracias a esta correspondencia, unas pocas cartas enviadas a su amigo, que podemos apreciar detalles de la vida cotidiana y personal del franciscano quien acude a sus amigos en ayuda de otros:

El Alférez real de esta Ciudad don Joseph de Urtiaga, mui mi amigo y Syndico nuestro, envía a esse real à cierta cobranza al portador de esta carta; yo le suplico a vuestra merced se sirva de patrocinarlo, protegerlo y aiudarlo, en lo que huviere lugar, que se lo estimare muchissimo y le quedare mui agradecido, por lo mucho que estimo a dicho Don Joseph, y respectos, que tengo para ello. Vuestra Merced me ha de perdonar la molestia, y ver en que puedo yo servirle, que lo haré con la veraz de amigo que de corazón lo estima mucho mucho ${ }^{80}$.

Argüelles, ese amigo del franciscano, estaba casado con María Antonia Sánchez de Tagle desde $1714^{81}$. María era hija de Pedro Sánchez de Tagle, Segundo Marqués de Altamira ${ }^{82}$, con quien al parecer por lo que se desprende de las cartas, el yerno tenía algunos problemas. Fray Ángel insistía con su amigo para que solucionase las desavenencias con el marqués, a quien nuestro franciscano llamaba cariñosamente compadre, tanto que envío las cartas a Juan Manuel que el propio

77 Podría tratarse de esta obra: Casarubios, 1619.

78 Por el interés que tiene este tipo de testimonio procuraremos publicar la correspondencia de Fray Ángel García Luque.

79 Carta de Fray Ángel García Duque. Querétaro, 28-XII-1723. AGN, Indiferente virreinal, Caja 5322, f. 1r.

80 Carta de Fray Ángel García Duque. Querétaro, 29-IV-1717. AGN, Indiferente virreinal, Caja 4872, exp. 23, f. $5 \mathrm{r}$.

81 México matrimonios, 1570-1950, Base de datos FamilySearch (https://familysearch.org/ark:/61903/1:1:JHGCS8F: 14 July 2015), Juan Manuel de Argüelles y Miranda con Maria Antonia Sánchez de Tagle, 13 Jun 1714; Asuncion, Mexico, Distrito Federal, Mexico, reference 2:1L2P5VL; FHL microfilm 35,271.

82 Goyas Mejías, 2011: 48. 
marqués había escrito "en dos pliegos" para el franciscano "ahogado de muchissimas pesadumbres" $"$.

Una falta de confidencia con un amigo para beneficio de otro, pues lo que se jugaba era la separación de un matrimonio, que no convenía "ni para Dios ni para el mundo". Estas, entre otras, son algunas de las palabras y noticias que un hombre de su tiempo nos proporciona a través de su correspondencia. Un tipo de testimonios en donde también podemos apreciar a un calificador del Santo Oficio, que es desenfadado en sus comentarios:

Digo aora, que estimo la noticia, y acepto el convite de mui buena gana, por ir a dar a vuestra merced un apretado abrazo; pero por estar tan cercano el dia de la Virgen Santissima, y tener yo tantas monjas, beatas y muchissma gente que confessar, no podre ir hasta que pase el domingo, que es el día de la Señora. El domingo por la tarde puede usted enviar dos bestias ensilladas muy mansas, que vengan el domingo de la noche a dormir en cassa de mi compadre, Don Juan Fernandez de los Rios (al Collegio que no lleguen) que el lunes (dia 16 del corriente) al romper el alva, saldré yo con mi compañero [...] y iremos el lunes (16) al medio día a comer con Vuestra Merced cuia vida guarde me Dios Nuestro Señor muchos años" $" 84$.

Este calificador, predicador, misionero y confesor, es un buen ejemplo de cómo podrían ser algunos calificadores responsables de la censura de libros en la Nueva España. A través de estas fuentes, dichas figuras de la censura en cierta forma se humanizan y, muestran a una sociedad que también explica por qué la Inquisición tuvo esas características y funciones. En efecto, las cartas privadas e institucionales pueden ser "un instrumento válido, y en muchos casos esencial, para conocer la vida cotidiana y social de una época" ${ }^{\prime 2}$.

Son testimonios que nos ayudan a entender a la Inquisición como una institución de su tiempo y, por tanto, acorde a los valores sociales, culturales y económicos de esa sociedad. En este sentido, "el sistema de control social de la Inquisición, fue mucho menos efectivo en aquellas zonas donde los beneficios para la población local superaban cualquier otro interés" 86 . Lo que incluía el ideológico o, el relacionado con la ortodoxia religiosa, no hay que olvidar que algunas cartas privadas también fueron usadas como testimonios en procedimientos inquisitoriales, ya fuese como denuncia o evidencia de un delito ${ }^{87}$.

Igualmente se escribieron cartas de los reos hacia los inquisidores, intentando obtener información sobre sus procesos o incluso cierta consideración mediante súplicas. Nexos familiares que se establecieron, pese a que las normas inquisitoriales prohibían de "modo taxativo que los reos recibieran o hicieran circular cualquier tipo de información"88. Así lo prueban numerosas cartas que todavía se conservan en el archivo inquisitorial del AGN. Por este medio, podemos adentrarnos en cier-

\footnotetext{
83 Carta de Fray Ángel García Duque. Querétaro, 16-VI-1717. AGN, Indiferente virreinal, caja 4872, exp. 23, f. 7r.

84 Carta de Fray Ángel García Duque. Querétaro, 11-VIII-1723. AGN, Indiferente Virreinal, Caja 4872, exp. 23, f. 16 r.

85 Ruiz Medrano, 2001: 17.

86 Thomas, 2001: 256.

87 Sánchez Rubio - Testón Núñez, 2014: 166.

88 Castillo Gómez, 2003: 149-150.
} 
tos debates entre inquisidores sobre sus tareas y responsabilidades. Conversaciones epistolares que no fueron casos extremadamente raros, algunos han sido estudiados como aquellos enfocados en determinar quién tenía mayor autoridad y jurisdicción en la publicación de los edictos de $\mathrm{fe}^{89}$.

Por otro lado, se trataba de una comunicación, entre reos y con los familiares de los procesados, que también revela aspectos que sin estas misivas quedarían sin rastro. Por ejemplo, la noticia que tenemos sobre algunos asuntos internos del taller de imprenta de Pedro Ocharte, durante su estadía en las cárceles de la Inquisición de México ${ }^{90}$. Un caso que nos permite entender lo anteriormente descrito. Bastaría comparar el tipo de penas y castigos que impresores de la misma época sufrieron en España durante el siglo XVI, frente a los casos presentados y juzgados en el tribunal novohispano. Ocharte y Cornelio Adriano César, pudieron volver a trabajar sin menoscabo de sus vidas. En este territorio se jugaban otros intereses que afectaron el trabajo de los inquisidores.

El control de los libros siempre fue una actividad compleja para el Santo Oficio. No sólo se trataba de educar en la conciencia del peligro que representaban ciertos libros, sino además fue necesario estructurar una compleja red compuesta por normativas institucionales, prácticas culturales y personas de todos los grupos sociales que participaron en esa estricta vigilancia sobre los libros. Las personas fueron el engranaje necesario para que la maquinaria inquisitorial funcionase durante más de doscientos años con bastante efectividad. Ciertamente las evidencias documentales que el Santo Oficio generó durante sus actividades en el territorio virreinal no muestran una persecución excesiva sobre ciertos tipos de libros. Por el contrario, se persiguieron y recogieron los libros que se ordenaban desde la Suprema. Empero, para encontrar todos esos "peligros librescos" requirieron de la participación de gentes del libro, como libreros e impresores, pero también del entramado eclesiástico.

De ahí que consideremos crucial interesarnos por las personas que ejercieron funciones en el Tribunal del Santo Oficio, tan particulares como la censura de libros. Sabemos tan poco de los calificadores y censores en Nueva España, fuera de aquellos que trabajaron en los años fundacionales. Todos ellos también fueron personas enfocadas en una formación, con intereses puntuales, y que transitaban entre la función inquisitorial y una vida privada ${ }^{91}$. No obstante, sobre ellos hemos cargado la parte más terrible de la leyenda negra y los hemos hecho responsables de estrangular el florecimiento del conocimiento en los territorios de la América española. Esa historia ahora muestra grietas y matices, en los que podríamos ahondar en los detalles.

\section{Referencias bibliográficas}

Bethencourt, Francisco. La Inquisición en la época moderna. Madrid: Akal, 1997.

Casarubios, Alfonso de. Compendium priuilegiorum fratrum minorum et aliorum mendicantium, \& non mendicantium, autore Alphonso de Casarubios Hispano... Per r.p.f. Hieronymum a Sorbo praedicatorem, ordinis Capuccinorum, et per eundem, eiusdem ordinis

\footnotetext{
89 Nesvig, 2009: 178-182.

$90 \quad$ Fernández del Castillo, 1914: 98-100.

91 Guibovich Pérez, 2004: 59.
} 
generalem, quibusdam additionibus locupletatum: qui etiam apposuit annotationes quasdam valde notabiles r.p.f. Antonij de Corduba... Quae omnia a mendis, quibus vndique scatebant, nunc omni curâ, \& diligentiâ sunt expurgata... addito duplici indice. Coloniae Agrippinae: apud Ioannem Kinchium sub Monocerote, 1619. CCPB000132698-8.

Castillo, Francisco del (O.S.A.). Migaias caydas de la mesa de los santos y doctores de la Iglesia: colegidas y aplicadas a todos los Euangelios de los santos... Pamplona: por Nicolas de Assiayn y a su costa impresso, 1620. CCPB000038894-7.

Castillo Gómez, Antonio. "Escrito en prisión: las escrituras carcelarias en los siglos XVI y XVII". Península. Revista de Estudios Ibéricos, no 0 (2003), 147-170.

- Leer y oír: ensayos sobre la lectura en los Siglos de Oro. Madrid: Iberoamericana, 2016.

Cathalogus librorum. Cathalogus librorum, qui prohibentur mandato Illustrissimi \& Reuerend. D. D. Ferdinandi de Valdes Hispalen. Archiepi, Inquisitoris Generalis Hispaniae... Pinciae: Quorum iussu \& licentia Sebastianus Martinez Excudebat, 1559. CCPB000004767-8.

Chica, Sebastian de la (O.F.M.). A B C de Jesús en la Escuela de María (sin nombre ni lugar de impresión).

García, Idalia. "El movimiento de los libros en la Nueva España: consideraciones sobre las fuentes inquisitoriales". Antrópica. Revista de Ciencias Sociales y Humanidades, Año 2, vol. 2, no 4 (julio-diciembre de 2016), 57-71. Disponible en https://www.antropica.com. mx/ojs/index.php/AntropicaRCSH/article/view/66

Dueñas, Juan de (O.F.M.). Espejo de consolacion: parte primera: en el qual se veran muchas y grandes hystorias de la sagrada escriptura, para consolacion de los que en esta vida padecen tribulacion... Burgos: por Iuan de Iunta: a costa del señor Iuan de Espinosa, mercader de libros vezino de Medina del Campo, 1546. CCPB000008493-X.

Ezcaray, Antonio de (O.F.M.). Vozes del dolor: nacidas de la mvltitvd de pecados, que se cometen por los trages profanos, afeytes, escotados, y culpables ornatos que en estos miserables tiempos, y en los antecedentes ha introducido el infernal Dragon para destruir, y acabar con las almas, que con su preciosissima Sangre redimiò nuestro amantissimo Jesus... Sevilla: por Thomas Lopez de Haro, a expensas de vnos amigos y hermanos espirituales del autor, 1691. CCPB000049733-9.

Fernández del Castillo, Francisco, Libros y libreros en el siglo XVI. México: Archivo General de la Nación, 1914.

García, Idalia - Montiel, Ana Cecilia. "Una vida entre cajones de libros: Felipe Pérez del Campo en la Nueva España". Estudios de Historia Novohispana, n. 43 (julio-diciembre de 2010), 51-107. Disponible en http://www.historicas.unam.mx/publicaciones/revistas/ novohispana/pdf/novo43/523.pdf.

García Duque, Ángel. (O.F.M.). Elogio sepulchral a las venerables memorias de el Padre Fr. Antonio de los Angeles que en el siglo se llamò don Antonio de Hoz Bustamante, de nacion montañez religioso lego, que vistiò el habito de N.S.P. San Francisco, professo, viviò y murió en el collegio de missioneros apostolicos, llamado la Santa Cruz de Queretaro, salió e esta vida á la eterna, como piadosamente se creè el dia 23 de el mes de junio del año de 1711... México: por los herederos de la viuda de Francisco Rodriguez Lupercio, 1712. JCB BA712.G216e.

Goyas Mejía, Ramón. "Notas sobre la vida de Pedro Sánchez de Tagle". Estudios de Historia Novohispana, no 45 (julio-diciembre 2011), 47-80. Disponible en http://www.historicas. unam.mx/publicaciones/revistas/novohispana/pdf/novo45/543.pdf.

Guibovich Pérez, Pedro Manuel. Censura, libros e inquisición en el Perú Colonial, 15701754. Sevilla: CSIC, Universidad de Sevilla, 2003. 
— "Custodios de la ortodoxia. Los calificadores de la Inquisición en Lima, Perú, 15701764”. Dimensión Antropológica, vol. 11, no 31 (2004), 59-78. Disponible en https:// www.revistas.inah.gob.mx/index.php/dimension/article/view/6007.

Hampe Martínez, Teodoro. "Una biblioteca cusqueña confiscada por la Inquisición. El proceso al doctor Agustín Valenciano de Quiñones, hereje reconciliado (1574-1595)". Revista Andina, vol. 5, no 2 (1987), 527-564. Disponible en http://www.revistaandinacbc.com/ wp-content/uploads/2016/ra10/ra-10-1987-05.pdf.

Lea, Charles. Historia de la Inquisición española. Madrid: Fundación Universitaria Española, 1983.

Maillard, Natalia. "Estrategias de los profesionales de libro sevillanos ante el Santo Oficio: entre la evasión y la colaboración”. En El libro en circulación en el mundo moderno en España y Latinoamérica, director Rueda Ramírez, Pedro. Madrid: Calambur, 2012, 23 44.

Mallea, Salvador de (O. SS. T.). Manual de Predicadores, y argumento sobre todos los PsaImos... [S.1.: s.n., s.a.]. CCPB000477338-1.

Marselaer, Frederik van. Frederici de Marselaer Equitis legatus libri duo. Amstelodami: apud Iodocum Iansonium, 1644. IT \ICCU\CFIE $\backslash 008851$.

Montesino. Ambrosio (O.F.M.). Epistolas y euangelios segun lo tiene y canta la santa madre Iglesia Romana, con sus doctrinas y sermones, compuesto por el reverendo padre fray Ambrosio de Montesino... agora nueuamente visto y corregido y puesto conforme el orden y estilo del missal y rezo romano de nuestro muy santo Padre Papa Pio V, por el R.P. fray Roman de Vallezillo, del Orden de san Benito... con tablas muy copiosas. Alcalá de Henares: en casa de Iuan Gracian, a costa de Diego Guillen, 1608. CCPB000821663-0.

Moreno Gamboa, Olivia. "Disonancias entre la Inquisición de México y la Suprema. A propósito de la censura del Ramillete de divinas flores (1690-1711)". En La dimensión imperial de la Iglesia novohispana, coordinadores Cervantes Bello, Francisco - Martínez López-Cano, María del Pilar. México: Benemérita Universidad Autónoma de Puebla, Instituto de Ciencias Sociales y Humanidades: UNAM, Instituto de Investigaciones Históricas, 2016, 165-198.

Nesvig, Martin. "Heretical Plagues and Censorship Cordons: Colonial Mexico and the Transatlantic Book Trade". Church History, vol. 75, nº 1 (2006), 1-37.

- Ideology and inquisition: the world of the censors in early Mexico. New Haven: Yale University Press, 2009.

Niño, Juanetin (O.F.M). A la Serenissima Señora Infanta Sor Margarita de la Cruz, Religiosa Descalça... en razon del interrogatorio en la causa de... Ana Maria de S. Joseph, Abadessa de lamesma Orden y provincia de Santiago en Salamanca. Salamanca: en la oficina de Jacinto Taberniel, impresor de la Universidad, 1632.

Novissimus librorum prohibitorum et expurgandorum index. Novissimus librorum prohibitorum et expurgandorum index pro catholicis hispaniarum regnis Philippi V..., 2 tomos. Matriti: Ex Typographia Musicae, 1707. CCPB000060149-7.

Pardo Tomás, José. Ciencia y censura: la Inquisición Española y los libros científicos en los siglos XVI-XVII. Madrid: Consejo Superior de Investigaciones de Investigaciones Científicas, 1991.

Peña Díaz, Manuel. Escribir y prohibir: Inquisición y censura en los Siglos de Oro. Madrid: Cátedra, 2015.

Plata Parga, Fernando. "Inquisición y censura en el siglo XVIII: el Parnaso español de Quevedo". La Perinola. Revista de Investigación Quevediana, nº 1 (1997), 173-188. Disponible en https://dadun.unav.edu/handle/10171/4551. 
Ramos, Alonso (S.I.). Tercera parte de los prodigios de la omnipotencia y milagros de la gracia en la vida de la U. Sierva de Dios Catharina de S. Joan natural del Gran Mogor, y difunta en esta imperial ciudad de la Puebla de los Angeles, en la Nueva-Espa$\tilde{n} a$... Mexico: en la casa professa, en la imprenta de Diego Fernandez de Leon, 1692. CCPB000500105-6.

Rodríguez Besné, José Ramón. El Consejo de la Suprema Inquisición: perfil jurídico de una institución. Madrid: Editorial Complutense, 2000.

Ruiz Medrano, Carlos Rubén. Fiestas y procesiones en el mundo colonial novohispano: los conflictos de preeminencia y una sátira de carnavalesca del siglo XVIII. San Luis Potosí: El Colegio de San Luis, 2001.

Sánchez Rubio, Rocío - Testón Núñez, Isabel. "Al servicio de la Inquisición. Cartas y correspondencia privada en el Tribunal de Nueva España durante el periodo moderno". En Cinco siglos de cartas: historia y prácticas epistolares en las épocas moderna y contemporánea, directores Castillo Gómez, Antonio - Sierra Blas, Verónica. Huelva: Universidad, 2014, 165-185.

Sarrion Mora, Adelina. Médicos e inquisición en el siglo XVII. Cuenca: Universidad de Castilla-La Mancha. 2006.

Schons, Dorothy. Book Censorship in New Spain. Ann Arbor: Edwards Brothers, 1949.

Septenario. Septenario del glorioso Patriarca Sr. S. Joseph, en reverencia de los siete dolores, y siete gozos: van añadidos los Exercicios en reverencia del augustissimo y divinissimo Sacramento para celebrarlo con perfección. Puebla: Por la viuda de Miguel de Ortega, 1729. BNChile III-19-C3(7).

Suboh Jarabo, Yasmina. "La revisión de las bibliotecas eclesiásticas españolas tras el edicto de 1747 y sus fondos espirituales y religiosos del siglo XVII español". Arte y patrimonio, $n^{o} 2$ (2017), 114-132. Disponible en https://helvia.uco.es/bitstream/handle/10396/15368/ arte_15.pdf? sequence $=1 \&$ isAllowed $=\mathrm{y}$

Thomas, Werner. Los Protestantes y la Inquisición en España en tiempos de Reforma y Contrarreforma. Leuven: Leuven University Press, 2001.

Torres Arce, Marina. La inquisición en su entorno: servidores del santo oficio de Logroño en el reinado de Felipe $V$. Santander: Universidad de Cantabria, 2001.

Urquiola Permisan, José Ignacio. "Francisco de Alzaga. Industria y agua en Querétaro, siglo XVIII". En Los vascos en las regiones de México (siglos XVI a XX), vol. 3, coordinado por Garritz, Amaya. México: UNAM, Ministerio de Cultura del Gobierno Vasco, Instituto Vasco Mexicano de Desarrollo, 1997, 111-129.

Vega, María José. “Coram simplicibus: disputatio y diálogo doctrinal en el pensamiento censorio del siglo XVI”. En Diálogo y censura en el siglo XVI (España y Portugal), al cuidado de Vian Herrero, Ana - Vega, María José - Friedlein, Roger. Madrid: Iberoamericana Vervuet, 2016, 73-104.

Velazquez Pinto, Antonio (CC.RR.MM.). Tesoro de los christianos que para dia les dexo Christo en el verdadero Maria Sacramento... Segunda Impression añadida por el mismo autor. Madrid: por Pablo de Val, 1664. CCPB000056254-8.

Wild, Johann (O.F.M.). Reuerendi Patris D. Ioannis Feri in totam Genesim... enarrationes. Louanii: excudebat Seruatius Sassenus: sumptibus haeredum Arnoldi Birckmanni \& Francisci Bohemi \& Sociorum. 1564. IT \ICCU\RMLE $\backslash 001738$. 